\title{
Correction to: "It is this very knowledge that makes us doctors": an applied thematic analysis of how medical students perceive the relevance of biomedical science knowledge to clinical medicine
}

\author{
Bonny L. Dickinson ${ }^{1 *}$, Kristine Gibson ${ }^{2}$, Kristi VanDerKolk ${ }^{3}$, Jeffrey Greene ${ }^{4}$, Claudia A. Rosu ${ }^{5}$, Deborah D. Navedo ${ }^{6}$,
} Kirsten A. Porter-Stransky ${ }^{7}$ and Lisa E. Graves ${ }^{3}$

\section{Correction to: BMC Med Educ 20, 356 (2020) https://doi.org/10.1186/s12909-020-02251-w}

Following publication of the original article [1], the authors Kristine Gibson, Jeffrey Greene and Lisa E. Graves changed their affiliations as follows:

Kristine Gibson

From: "Department of Family and Community Medicine, Western Michigan University Homer Stryker M.D. School of Medicine, Kalamazoo, MI, USA.“

To: "Department of Pediatric and Adolescent Medicine, Western Michigan University Homer Stryker M.D. School of Medicine, Kalamazoo, MI, USA."

\section{Jeffrey Greene}

From: "Department of Family and Community Medicine, Western Michigan University Homer Stryker M.D. School of Medicine, Kalamazoo, MI, USA."

To: "Department of Medical Education, Western Michigan University Homer Stryker M.D. School of Medicine, Kalamazoo, MI, USA."

The original article can be found online at https://doi.org/10.1186/s12909020-02251-w.

* Correspondence: dickinson_bl@mercer.edu

${ }^{1}$ Department of Biomedical Sciences, Mercer University School of Medicine, Macon, GA, USA

Full list of author information is available at the end of the article
Lisa E. Graves

From: "Department of Biomedical Sciences, Mercer University School of Medicine, Macon, GA, USA"

To:" Department of Family and Community Medicine, Western Michigan University Homer Stryker M.D. School of Medicine, Kalamazoo, MI, USA."

The author group has been updated above.

\begin{abstract}
Author details
'Department of Biomedical Sciences, Mercer University School of Medicine, Macon, GA, USA. ${ }^{2}$ Department of Pediatric and Adolescent Medicine, Western Michigan University Homer Stryker M.D. School of Medicine, Kalamazoo, MI, USA. ${ }^{3}$ Department of Family and Community Medicine, Western Michigan University Homer Stryker M.D. School of Medicine, Kalamazoo, MI, USA. ${ }^{4}$ Department of Medical Education, Western Michigan University Homer Stryker M.D. School of Medicine, Kalamazoo, MI, USA. ${ }^{5}$ Center for Interprofessional Studies and Innovation at Massachusetts General Hospital Institute of Health Professions, Boston, MA, USA. ${ }^{6}$ Massachusetts General Hospital, Learning Laboratory, Massachusetts General Hospital, Boston, MA, USA. ${ }^{7}$ Department of Biomedical Sciences, Western Michigan University Homer Stryker M.D. School of Medicine, Kalamazoo, MI, USA.
\end{abstract}

Published online: 13 November 2020

Reference

1. Dickinson BL, et al. "It is this very knowledge that makes us doctors": an applied thematic analysis of how medical students perceive the relevance of biomedical science knowledge to clinical medicine. BMC Med Educ. 2020;20:356. https://doi.org/10.1186/s12909-020-02251-w.

C C The Author(s). 2020 Open Access This article is licensed under a Creative Commons Attribution 4.0 International License, which permits use, sharing, adaptation, distribution and reproduction in any medium or format, as long as you give appropriate credit to the original author(s) and the source, provide a link to the Creative Commons licence, and indicate if changes were made. The images or other third party material in this article are included in the article's Creative Commons licence, unless indicated otherwise in a credit line to the material. If material is not included in the article's Creative Commons licence and your intended use is not permitted by statutory regulation or exceeds the permitted use, you will need to obtain permission directly from the copyright holder. To view a copy of this licence, visit http://creativecommons.org/licenses/by/4.0/ The Creative Commons Public Domain Dedication waiver (http://creativecommons.org/publicdomain/zero/1.0/) applies to the data made available in this article, unless otherwise stated in a credit line to the data. 